\title{
Safe implementation of robotic gastrectomy for gastric cancer under the requirements for universal health insurance coverage: a retrospective cohort study using a nationwide registry database in Japan
}

\author{
Koichi Suda ${ }^{1,2}(10) \cdot$ Hiroyuki Yamamoto $^{3} \cdot$ Tatsuto Nishigori $^{4} \cdot$ Kazutaka Obama $^{4} \cdot$ Yukie Yoda $^{5} \cdot$ Makoto Hikage $^{6} \cdot$ \\ Susumu Shibasaki ${ }^{1} \cdot$ Tsuyoshi Tanaka $^{7} \cdot$ Yoshihiro Kakeji $^{8} \cdot$ Masafumi Inomata $^{9} \cdot$ Yuko Kitagawa $^{10} \cdot$ Hiroaki Miyata $^{3}$. \\ Masanori Terashima ${ }^{6} \cdot$ Hirokazu Noshiro $^{5} \cdot$ Ichiro Uyama $^{7,11}$
}

Received: 11 September 2021 / Accepted: 1 October 2021 / Published online: 12 October 2021

(c) The International Gastric Cancer Association and The Japanese Gastric Cancer Association 2021

\begin{abstract}
Background Robotic gastrectomy (RG) has increased since being covered by universal health insurance in 2018. However, to ensure patient safety the operating surgeon and facility must meet specific requirements. We aimed to determine whether RG has been safely implemented under the requirements for universal health insurance in Japan.

Methods Data of consecutive patients with primary gastric cancer who underwent minimally invasive total or distal gastrectomy_performed by a surgeon certified by the Japan Society for Endoscopic Surgery (JSES) endoscopic surgical skill qualification system (ESSQS) between October 2018 and December 2019-were extracted from the gastrointestinal surgery section of the National Clinical Database (NCD). The primary outcome was morbidity over Clavien-Dindo classification grade IIIa. Patient demographics and hospital volume were matched between RG and laparoscopic gastrectomy (LG) using propensity score-matched analysis (PSM), and the short-term outcomes of RG and LG were compared.

Results After PSM, 2671 patients who underwent RG and 2671 who underwent LG were retrieved (from a total of 9881), and the standardized difference of all the confounding factors reduced to 0.07 or less. Morbidity rates did not differ between the RG and LG patients (RG, $4.9 \%$ vs. LG, 3.9\%; $p=0.084$ ). No difference was observed in 30-day mortality (RG, $0.2 \%$ vs. LG, $0.1 \% ; p=0.754)$. The reoperation rate was greater following RG (RG, $2.2 \%$ vs. $\mathrm{LG}, 1.2 \% ; p=0.004)$; however, the duration of postoperative hospitalization was shorter (RG, 10 [8-13] days vs. LG, 11 [9-14] days; $p<0.001$ ).
\end{abstract}

Conclusions Insurance-covered RG has been safely implemented nationwide.

Keywords Stomach neoplasms · Gastrectomy · Robotic surgical procedure - Minimally invasive surgical procedures · Postoperative complications

Koichi Suda

ko-suda@nifty.com

1 Department of Surgery, Fujita Health University, 1-98 Dengakugakubo, Kutsukake, Toyoake, Aichi 470-1192, Japan

2 Collaborative Laboratory for Research and Development in Advanced Surgical Intelligence, Fujita Health University, Toyoake, Japan

3 Department of Healthcare Quality Assessment, Graduate School of Medicine, The University of Tokyo, Tokyo, Japan

4 Department of Surgery, Graduate School of Medicine, Kyoto University, Kyoto, Japan

5 Department of Surgery, Saga University Faculty of Medicine, Saga, Japan
6 Division of Gastric Surgery, Shizuoka Cancer Center, Shizuoka, Japan

7 Collaborative Laboratory for Research and Development in Advanced Surgical Technology, Fujita Health University, Toyoake, Japan

8 Database Committee, The Japanese Society of Gastroenterological Surgery, Tokyo, Japan

9 Academic Committee, The Japan Society for Endoscopic Surgery, Tokyo, Japan

10 The Japanese Society of Gastroenterological Surgery, Tokyo, Japan

11 Department of Advanced Robotic and Endoscopic Surgery, Fujita Health University, Toyoake, Japan 


\section{Abbreviations}

$\begin{array}{ll}\text { GC } & \text { Gastric cancer } \\ \text { LG } & \text { Laparoscopic gastrectomy } \\ \text { RG } & \text { Robotic gastrectomy } \\ \text { DVSS } & \text { Da Vinci surgical system } \\ \text { MHLW } & \text { Ministry of Health, Labor, and Welfare } \\ \text { C-D } & \text { Clavien-Dindo classification } \\ \text { JSES } & \text { Japan Society for Endoscopic Surgery } \\ \text { ESSQS } & \text { Endoscopic Surgical Skill Qualification System } \\ \text { JSGS } & \text { Japanese Society of Gastroenterological } \\ & \text { Surgery } \\ \text { NCD } & \text { National Clinical Database } \\ \text { RTG } & \text { Robotic total gastrectomy } \\ \text { LTG } & \text { Laparoscopic total gastrectomy } \\ \text { RDG } & \text { Robotic distal gastrectomy } \\ \text { LDG } & \text { Laparoscopic distal gastrectomy } \\ \text { DG } & \text { Distal gastrectomy } \\ \text { PG } & \text { Proximal gastrectomy } \\ \text { PSM } & \text { Propensity score matched analysis } \\ \text { ASA-PS } & \text { American Society of Anesthesiologists physical } \\ & \text { status } \\ \text { TG } & \text { Total gastrectomy } \\ \text { SD } & \text { Standardized difference } \\ \text { OR } & \text { Odds ratio } \\ \text { CI } & \text { Confidence interval } \\ \text { CTCAE } & \text { Common Terminology Criteria for Adverse } \\ & \text { Events }\end{array}$

\section{Introduction}

Gastric cancer (GC) is the fifth most common cancer and the fourth leading cause of cancer-related death worldwide [1]. Surgical resection is the only curative treatment approach, with regional lymphadenectomy recommended as part of radical gastrectomy [2]. Laparoscopic gastrectomy (LG) is increasingly used because of its beneficial short-term effects compared with open gastrectomy [3].

The da Vinci surgical system (DVSS) was developed to overcome the disadvantages with standard minimally invasive surgery using a laparoscope [2]. In our previous multi-institutional prospective study (UMIN000015388) which was approved for Advanced Medical Technology ("Senshiniryo B") managed by the Ministry of Health, Labour, and Welfare (MHLW) - we successfully showed that robotic gastrectomy (RG) for cStage I/II GC reduced the morbidity rate (Clavien-Dindo classification [C-D] grade $\geq$ IIIa) of LG to less than half of that in a historical control with data from three leading institutions of LG, including Kyoto, Saga, and Fujita health universities [4]. Consequently, the MHLW decided to recognize 12 more robotic procedures, including RG, as part of their corresponding conventional minimally invasive procedures from the standpoint of medical insurance coverage as of April 2018 [5]. Since then, the number of RGs have dramatically increased nationwide, although the following requirements were set for the surgery to be covered by the insurance, to restrict the introduction of surgeries in inexperienced institutions: (1) the operating surgeon should be qualified by the Japan Society for Endoscopic Surgery (JSES) endoscopic surgical skill qualification system (ESSQS) [6], as well as board-certified in gastroenterology by the Japanese Society of Gastroenterological Surgery (JSGS). (2) The operating surgeon should have performed more than $10 \mathrm{RGs}$, including robotic distal, proximal, and total gastrectomy. (3) The facility must have performed more than 50 gastrectomies including 20 laparoscopic or robotic distal, proximal, or total gastrectomies during the past year [5, 7]. Actually, in the Japanese universal health insurance system, the services covered and the fees set for physicians and hospitals have been uniform across the nation [8]. A patient basically pays $30 \%$ of the fee schedule price, and, when the monthly co-payment exceeds a threshold amount, the co-payment for a patient in an average-income family is decreased to $80,100+$ (medical expense $-267,000) \times 0.01 \mathrm{JPY} / \mathrm{month}$ (high-cost medical expense benefit) [8, 9]. In the meantime, the Japanese government prohibits joint provision of medical treatments covered by the universal health insurance and those not covered [2]. Therefore, a patient who undergoes uninsured RG is required to pay approximately 2,200,000 JPY, whereas a patient who undergoes insured RG, similar to those who undergo LG, is charged approximately 100,000 JPY during perioperative admission in any hospital.

The Japanese National Clinical Database (NCD), which started its data registration in 2011, has grown into a large nationwide database covering more than $95 \%$ of the surgeries performed by regular surgeons in Japan [10]. As of the end of December 2019, 5276 facilities have been enrolled in the NCD, and approximately 1,500,000 cases have been registered every year [10]. Since enrolled cases are linked to a lifelong board certification system for surgeons, data registration to the NCD is mandatory for teaching hospitals and for community hospitals with surgical departments throughout Japan [11]. The NCD has collected demographical data, procedural details, and perioperative variables that are almost identical to those of the American College of Surgeons' National Surgical Quality Improvement Program [12]. In October 2018, the NCD-based prospective registry system for patients who were scheduled to undergo RG was launched under the leadership of the MHLW and JSES, and the registration of each patient to obtain insurance coverage for the surgery was mandated [5]. Therefore, the aim of the present study was to determine, by examining data from the $\mathrm{NCD}$, whether RG under the national insurance program has been safely implemented nationwide. 


\section{Materials and methods}

\section{Data source}

The NCD collects data on patient demographics, pre-existing comorbidities, preoperative laboratory values and perioperative data, including the clinical course for up to 90 days after surgery [12]. Participating institutions can access all NCD variables, definitions, and inclusion criteria online [13]. An annual educational meeting for data managers and an e-learning system to achieve consistency in data entry is also provided. Data consistency is validated through inspections of randomly chosen institutions and assurance of data traceability using the web-based data management system [12]. Clinical staging was performed preoperatively according to the 8th edition of the Union for International Cancer Control-TNM classification [14].

\section{Study design and cohort development}

Consecutive patients with primary gastric cancer who underwent minimally invasive total or distal gastrectomy (robotic total gastrectomy, RTG; laparoscopic total gastrectomy, LTG; robotic distal gastrectomy, RDG; laparoscopic distal gastrectomy, LDG), performed by a surgeon qualified by the JSES ESSQS, between October 2018 and December 2019 were retrieved from the gastrointestinal surgery section of the NCD. Distal gastrectomy (DG) includes pylorus-preserving gastrectomy and segmental gastrectomy. Those who underwent proximal gastrectomy (PG) were not enrolled because detailed short-term outcomes of PG were not recorded in this database. The JSES provided the JSGS, who administrates the gastroenterological section of the NCD, with a list of the medical license number of each surgeon qualified by the JSES ESSQS. The following exclusion criteria were set to focus on the surgical outcomes of gastrectomy with curative intent: (1) cStage IV (cT4b or cM1); (2) cTx, Nx, or Mx; (3) esophagogastric junction cancer with a length of esophageal invasion $>30 \mathrm{~mm}$; (4) emergency surgery; (5) disseminated cancer; (6) concurrent surgical procedures except for cholecystectomy, splenectomy, enterostomy, local resection of the stomach, esophageal hiatal hernia repair, fundoplication, and central venous port placement; and (7) patients who declined publication of their treatment information or had insufficient follow-up.

\section{Selection of quality indicators and confounding factors}

Consensus meetings were held by a study team consisting of surgeons and biostatisticians to determine quality indicators, adjust for confounding factors, and enable the comparison of surgical outcomes between RG and LG using propensity score matched analysis (PSM). The primary outcome was the morbidity rate within 30 days of surgery, determined by C-D grade IIIa or higher [15]. We selected this outcome measure, because postoperative complications requiring surgical, endoscopic, or radiological intervention, which correspond to $\mathrm{C}-\mathrm{D}$ grade IIIa, remarkably extend the admission period, threaten the patient's life, and increase medical cost [15-17]. The secondary outcomes were surgical outcomes, including open surgery conversion rate, incident of intraoperative adverse events (cardiopulmonary arrest, myocardial infarction), operative time, estimated blood loss, massive intraoperative bleeding ( $\geq 1000 \mathrm{~mL}$ ), intraoperative use of blood transfusion, and intraoperative use of red blood cell transfusions, and surgical curativity (R0, R1, R2); incidence of each postoperative complication, including intra-abdominal infectious complications (anastomotic leakage, pancreatic fistula, intra-abdominal abscess), other local complications (pancreatitis, superficial incisional surgical site infection, deep incisional surgical site infection, wound dehiscence, intra-abdominal bleeding, anastomotic stenosis, functional and mechanical small bowel obstruction, anastomotic ulcer, gastroduodenal ulcer, and intestinal bleeding), and systemic complications (pneumonia, peritonitis not caused by intra-abdominal infectious complications, unexpected endotracheal intubation, pulmonary embolism, ventilator dependency, cardiac arrest requiring cardiopulmonary resuscitation, postoperative blood transfusion, deep venous thrombosis, sepsis, atelectasis, cardiac decompensation, disseminated intravascular coagulation, pleural empyema, tracheal necrosis, liver failure, refractory ascites, and liver abscess); duration of intensive care unit stay; duration of postoperative hospitalization; reoperation rate within 30 days after surgery; readmission rate within 30 days after surgery; 30-day mortality, defined as any death within 30 days after surgery; in-hospital mortality within 90 days after surgery; and surgical mortality, which included all patients who died within 30 days of operation or those who died during hospitalization within 90 days after surgery.

Preoperative factors that served as a basis for determining the allocation to either robotic or laparoscopic surgery were identified to estimate propensity scores. Several additional risk predictors identified in a previous study were also included in the model [11, 18-22]. As a result, covariates for propensity score estimation included patient age at the time of surgery, sex, body mass index, the American Society of Anesthesiologists physical status (ASA-PS), activities of daily living, smoking status, and presence of habitual alcohol intake. Furthermore, we also included preoperative conditions, including weight loss 
greater than $10 \%$ within the past 6 months; presence of comorbidities such as any respiratory distress, mechanical ventilator dependency within $48 \mathrm{~h}$ of operation, insulindependent diabetes mellitus, chronic obstructive pulmonary disease, hypertension within 30 days of operation, congestive heart failure within 30 days of operation, angina within 30 days of operation, history of myocardial infarction within 6 months of surgery, previous cardiovascular surgery, need for preoperative dialysis within 14 days of operation, previous cerebrovascular accident, chronic steroid use, bleeding risk factors, preoperative sepsis, and laboratory data (white blood cell count, hemoglobin, platelet count, albumin, alkaline phosphatase, creatinine, sodium, C-reactive protein, and prothrombin time). Factors such as cT and cN categories, type of resection (DG or total gastrectomy [TG]), esophagogastric junction cancer, presence of concurrent cholecystectomy, splenectomy and enterostomy, use of preoperative chemotherapy, and hospital case volume were also considered. Hospital case volume was determined based on the mean annual number of minimally invasive procedures, including RDG, RTG, LDG, and LTG, which were estimated using the database. Hospital case volume $\geq 20$ cases/year was recognized as a high-to-middle volume in this study.

\section{Statistical analysis}

A biostatistician (H. Y.) conducted propensity score modeling and matching while being blinded to the outcome. The propensity score was estimated using logistic regression models built separately in the cohort of DG cases and that of TG cases, predicting the exposure of undergoing RG to LG from the confounding variables described above. Greedy nearest neighbor matching was performed using a caliper with 0.2 standard deviations of the logit of the estimated propensity score at a ratio of 1:1 without replacement using the PSMATCH2 program [23]. The balance of the matched cohort was assessed by calculating the standardized difference (SD) between the two groups using the STDDIFF program [24]. An absolute SD above 0.1 indicated a meaningful imbalance. We made comparisons of various outcomes between the matched cohort using McNemar's test or the StuartMaxwell test for categorical variables and the Wilcoxon signed-rank test for continuous variables. A conditional logistic regression model was applied to estimate the odds ratio (OR) and $95 \%$ confidence interval $(95 \% \mathrm{CI})$ of the primary outcome. Data are expressed as median (interquartile range) unless otherwise stated. All comparisons were two-sided, and a $p$ value less than 0.05 was considered significant. All analyses were conducted using STATA 16 (STATA Corp., TX, USA).

\section{Results}

\section{Patient demographics}

A flow diagram of the patient selection process is shown in Fig. 1. During the study period, 10,722 patients who underwent RDG, LDG, RTG, or LTG were registered in the NCD. Of these, 841 patients were excluded, and the remaining 9881 patients, consisting of 2675 RGs and 7206 LGs, underwent the analyses. The background characteristics of the patients are summarized in Table 1. Patients who were treated by RG were younger, had a better activities of daily living score and less advanced disease, with fewer ASA-PS scores of 3-5. A greater proportion of patients treated with RG underwent DG (RG, $85.5 \%$ vs. LG, 79.8\%), whereas a smaller proportion underwent concurrent surgical procedures (RG, $4.4 \%$ vs. LG, $11.8 \%$ ). Moreover, RG was more likely to be performed in highto-middle volume hospitals in relation to minimally invasive gastrectomy (RG, $98.1 \%$ vs. LG, $79.5 \%$ ). After the propensity score matching, 2671 patients who underwent RG and 2671 who underwent LG were retrieved, and the SD of all these confounding factors was reduced to 0.07 or less (Table 1).

\section{Surgical outcomes}

Surgical outcomes are shown in Table 2. The operative time was significantly longer in RG (RG, 354 [295-426] min vs. LG, 268 [221-326] min; $p<0.001)$, whereas no differences were seen between RG and LG in open surgery conversion rate, incidence of intraoperative adverse events, estimated blood loss, massive intraoperative bleeding, intraoperative use of blood transfusion, intraoperative use of red blood cell transfusions, and surgical curativity.

\section{Short-term outcomes after surgery}

The postoperative short-term outcomes are shown in Table 3 . The morbidity rate (C-D grade $\geq$ IIIa), which was the primary outcome of this study, did not differ between RG and LG (RG, $4.9 \%$ vs. LG, $3.9 \%$; OR, 1.27 ; $95 \%$ CI $0.977-1.650 ; p=0.084)$. No differences were observed in intra-abdominal infectious complications (RG, 5.0\% vs. LG, $5.4 \%$; $p=0.533$ ), other local complications (RG, $4.1 \%$ vs. $L G, 4.0 \% ; p=0.944)$, and systemic complications (RG, $3.7 \%$ vs. LG, $3.4 \%$; $p=0.602$ ). The reoperation rate was greater in RG (RG, $2.2 \%$ vs. LG, $1.2 \%$; $p=0.004$ ); however, the duration of postoperative hospitalization was 
Fig. 1 Flow diagram of the patient selection process. $D G$ distal gastrectomy, $T G$ total gastrectomy, ESSQS Endoscopic Surgical Skill Qualification System, $R G$ robotic gastrectomy, $L G$ laparoscopic gastrectomy, $R D G$ robotic distal gastrectomy, $R T G$ robotic total gastrectomy, $L D G$ laparoscopic distal gastrectomy, $L T G$ laparoscopic total gastrectomy

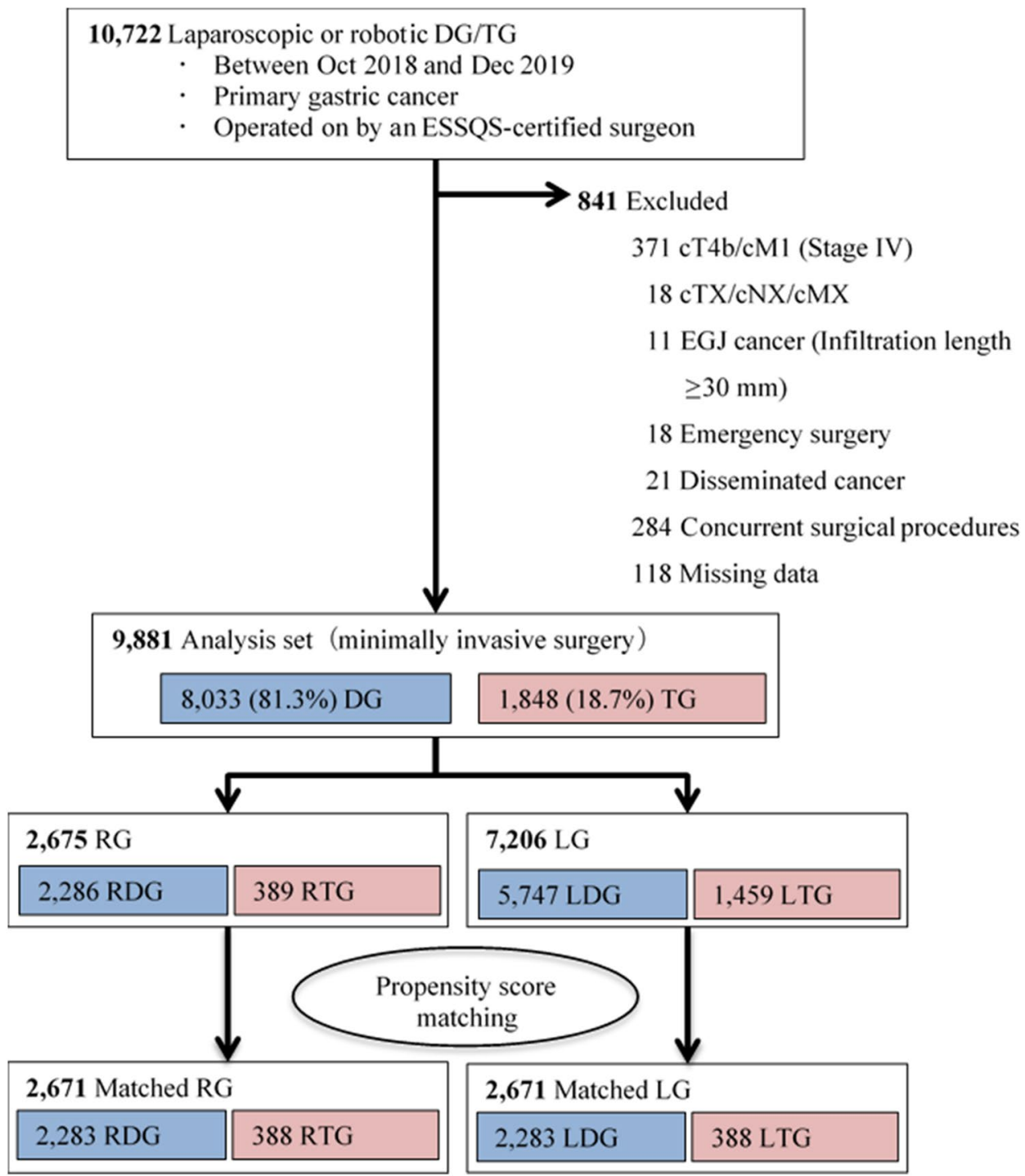

shorter in RG (RG, 10 [8-13] days vs. LG, 11 [9-14] days; $p<0.001)$. There was no difference in intensive care unit stay duration, readmission rate, 30-day mortality, inhospital mortality, and surgical mortality in this series. In addition, the parameters for each type of resection are summarized in Table 4.

\section{Discussion}

The present large database study clearly demonstrated the safe real-world penetration of RG under the Japanese universal health insurance program. In the NCD, detailed patient demographic data are recorded, including age, sex, tumor stage, comorbidities, clinical laboratory data, type of operation, and preoperative treatment; these were elaborately balanced between RG and LG groups using PSM in this study [11, 12, 18-21]. It has been reported that surgeon and hospital volume, as well as patient demographics, affect the outcomes of surgical treatment [20, 22]. Operating surgeons in both LG and RG groups were confined to those qualified by the JSES ESSQS to control for the surgeon volume; to be covered by insurance, RGs during this study period had to be performed by ESSQS-qualified surgeons, who have been regarded as highly skilled in laparoscopic surgery and thoroughly familiar with operative anatomy and LG procedure [7]. According to a previous study, ESSQS qualification is positively associated with LG case experience and proficiency in the LG procedure [25]. Moreover, experienced LG surgeons can overcome the learning curve of RG more rapidly [26-28]. Hospital volume was adjusted using PSM by categorizing annual minimally invasive gastrectomy ( $\mathrm{LG}+\mathrm{RG}$ ) cases into above (high-to-middle volume) and below (low-volume) 20 because for RGs to be covered by insurance, the operating hospital must have performed more than 20 minimally invasive gastrectomies during the past 
Table 1 Patient background

\begin{tabular}{|c|c|c|c|c|c|c|}
\hline & \multicolumn{3}{|c|}{ Before matching } & \multicolumn{3}{|l|}{ After matching } \\
\hline & \multicolumn{2}{|l|}{ No. $(\%)$} & \multirow[t]{2}{*}{ SD } & \multicolumn{2}{|l|}{ No. $(\%)$} & \multirow[t]{2}{*}{ SD } \\
\hline & $\mathrm{RG}(n=2675)$ & LG $(n=7206)$ & & $\mathrm{RG}(n=2671)$ & LG $(n=2671)$ & \\
\hline \multicolumn{7}{|l|}{ Age, years } \\
\hline$<60$ & $572(21.4 \%)$ & $1125(15.6 \%)$ & 0.224 & $572(21.4 \%)$ & $579(21.7 \%)$ & 0.038 \\
\hline $60-64$ & $290(10.8 \%)$ & $700(9.7 \%)$ & & $290(10.9 \%)$ & $318(11.9 \%)$ & \\
\hline $65-69$ & $450(16.8 \%)$ & $1231(17.1 \%)$ & & $449(16.8 \%)$ & $440(16.5 \%)$ & \\
\hline $70-74$ & $578(21.6 \%)$ & $1453(20.2 \%)$ & & $577(21.6 \%)$ & $557(20.9 \%)$ & \\
\hline $75-79$ & $442(16.5 \%)$ & $1283(17.8 \%)$ & & $441(16.5 \%)$ & $431(16.1 \%)$ & \\
\hline$\geq 80$ & $343(12.8 \%)$ & $1414(19.6 \%)$ & & $342(12.8 \%)$ & $346(13.0 \%)$ & \\
\hline \multicolumn{7}{|l|}{ Sex } \\
\hline Female & $913(34.1 \%)$ & $2351(32.6 \%)$ & 0.032 & $911(34.1 \%)$ & $917(34.3 \%)$ & -0.005 \\
\hline \multicolumn{7}{|l|}{ BMI, $\mathrm{kg} / \mathrm{m}^{2}$} \\
\hline$<18.5$ & $235(8.8 \%)$ & $664(9.2 \%)$ & 0.061 & $235(8.8 \%)$ & $244(9.1 \%)$ & 0.030 \\
\hline $18.5 \leq \mathrm{BMI}<25$ & $1850(69.2 \%)$ & $4784(66.4 \%)$ & & $1846(69.1 \%)$ & $1809(67.7 \%)$ & \\
\hline$\geq 25$ & $590(22.1 \%)$ & $1758(24.4 \%)$ & & $590(22.1 \%)$ & $618(23.1 \%)$ & \\
\hline \multicolumn{7}{|l|}{ ASA-PS } \\
\hline $3-5$ & $163(6.1 \%)$ & $845(11.7 \%)$ & 0.199 & $163(6.1 \%)$ & $160(6.0 \%)$ & -0.005 \\
\hline \multicolumn{7}{|l|}{$\mathrm{ADL}^{\mathrm{a}}$} \\
\hline With any assistance & $27(1.0 \%)$ & $195(2.7 \%)$ & 0.126 & $27(1.0 \%)$ & $23(0.9 \%)$ & -0.016 \\
\hline Smoking $^{\mathrm{b}}$ & $568(21.2 \%)$ & $1554(21.6 \%)$ & 0.008 & $567(21.2 \%)$ & $575(21.5 \%)$ & 0.007 \\
\hline Habitual alcohol intake & $1609(60.1 \%)$ & $3847(53.4 \%)$ & -0.137 & $1607(60.2 \%)$ & $1583(59.3 \%)$ & -0.018 \\
\hline Weight loss $>10 \%^{\mathrm{c}}$ & $37(1.4 \%)$ & $138(1.9 \%)$ & 0.042 & $37(1.4 \%)$ & $39(1.5 \%)$ & 0.006 \\
\hline \multicolumn{7}{|l|}{ Comorbidities } \\
\hline Respiratory distress ${ }^{\mathrm{d}}$ & $15(0.6 \%)$ & $79(1.1 \%)$ & 0.059 & $15(0.6 \%)$ & $17(0.6 \%)$ & 0.010 \\
\hline Ventilator dependency ${ }^{\mathrm{e}}$ & $0(0.0 \%)$ & $0(0.0 \%)$ & - & $0(0.0 \%)$ & $0(0.0 \%)$ & - \\
\hline Diabetes mellitus (insulin-dependent) & $67(2.5 \%)$ & $203(2.8 \%)$ & 0.019 & $66(2.5 \%)$ & $61(2.3 \%)$ & -0.012 \\
\hline COPD & $148(5.5 \%)$ & $377(5.2 \%)$ & -0.013 & $148(5.5 \%)$ & $145(5.4 \%)$ & -0.005 \\
\hline Hypertension $^{\mathrm{d}}$ & $1041(38.9 \%)$ & $3171(44.0 \%)$ & 0.103 & $1041(39.0 \%)$ & $1035(38.7 \%)$ & -0.005 \\
\hline Congestive heart failure $^{\mathrm{d}}$ & $4(0.1 \%)$ & $29(0.4 \%)$ & 0.048 & $4(0.1 \%)$ & $5(0.2 \%)$ & 0.009 \\
\hline Angina $^{\mathrm{d}}$ & $27(1.0 \%)$ & $62(0.9 \%)$ & -0.015 & $27(1.0 \%)$ & $19(0.7 \%)$ & -0.032 \\
\hline History of myocardial infarction ${ }^{c}$ & $7(0.3 \%)$ & $22(0.3 \%)$ & 0.008 & $7(0.3 \%)$ & $3(0.1 \%)$ & -0.035 \\
\hline Previous cardiovascular surgery & $28(1.0 \%)$ & $92(1.3 \%)$ & 0.021 & $28(1.0 \%)$ & $31(1.2 \%)$ & 0.011 \\
\hline Hemodialysis $^{\mathrm{f}}$ & $4(0.1 \%)$ & $47(0.7 \%)$ & 0.080 & $4(0.1 \%)$ & $3(0.1 \%)$ & -0.010 \\
\hline Previous cerebrovascular accident & $97(3.6 \%)$ & $332(4.6 \%)$ & 0.049 & $97(3.6 \%)$ & $96(3.6 \%)$ & -0.002 \\
\hline Chronic steroid use & $30(1.1 \%)$ & $95(1.3 \%)$ & 0.018 & $30(1.1 \%)$ & $24(0.9 \%)$ & -0.022 \\
\hline Bleeding risk factor $^{\mathrm{a}}$ & $89(3.3 \%)$ & $236(3.3 \%)$ & -0.003 & $89(3.3 \%)$ & $77(2.9 \%)$ & -0.026 \\
\hline Sepsis $^{\mathrm{a}}$ & $4(0.1 \%)$ & $0(0.0 \%)$ & -0.055 & $0(0.0 \%)$ & $0(0.0 \%)$ & - \\
\hline \multicolumn{7}{|l|}{ Clinical laboratory data ${ }^{\mathrm{g}}$} \\
\hline White blood cell count $>9000 / \mu \mathrm{L}$ & $114(4.3 \%)$ & $361(5.0 \%)$ & 0.036 & $114(4.3 \%)$ & $100(3.7 \%)$ & -0.027 \\
\hline Hemoglobin $<10 \mathrm{~g} / \mathrm{dL}$ & $136(5.1 \%)$ & $641(8.9 \%)$ & 0.150 & $136(5.1 \%)$ & $138(5.2 \%)$ & 0.003 \\
\hline Platelet count $<10 \times 10^{4} / \mu \mathrm{L}$ & $16(0.6 \%)$ & $75(1.0 \%)$ & 0.049 & $16(0.6 \%)$ & $13(0.5 \%)$ & -0.015 \\
\hline Albumin $<2.5 \mathrm{~g} / \mathrm{dL}$ & $12(0.4 \%)$ & $56(0.8 \%)$ & 0.042 & $12(0.4 \%)$ & $11(0.4 \%)$ & -0.006 \\
\hline Alkaline phosphatase $>340 \mathrm{U} / \mathrm{L}$ & $131(4.9 \%)$ & $422(5.9 \%)$ & 0.043 & $131(4.9 \%)$ & $122(4.6 \%)$ & -0.016 \\
\hline Creatinine $>1.2 \mathrm{mg} / \mathrm{dL}$ & $139(5.2 \%)$ & $563(7.8 \%)$ & 0.106 & $139(5.2 \%)$ & $122(4.6 \%)$ & -0.030 \\
\hline Sodium < 138 mEq/L & $116(4.3 \%)$ & $462(6.4 \%)$ & 0.092 & $115(4.3 \%)$ & $115(4.3 \%)$ & 0.000 \\
\hline C-reactive protein $>1.0 \mathrm{mg} / \mathrm{dL}$ & $96(3.6 \%)$ & $410(5.7 \%)$ & 0.100 & $96(3.6 \%)$ & $87(3.3 \%)$ & -0.019 \\
\hline PT-INR $>1.1$ & $65(2.4 \%)$ & $320(4.4 \%)$ & 0.111 & $65(2.4 \%)$ & $67(2.5 \%)$ & 0.005 \\
\hline \multicolumn{7}{|l|}{ Clinical $\mathrm{T}$ factor ${ }^{\mathrm{h}}$} \\
\hline$\leq \mathrm{T} 1$ & $1666(62.3 \%)$ & $4151(57.6 \%)$ & 0.148 & $1664(62.3 \%)$ & $1736(65.0 \%)$ & 0.060 \\
\hline
\end{tabular}


Table 1 (continued)

\begin{tabular}{|c|c|c|c|c|c|c|}
\hline & \multicolumn{3}{|c|}{ Before matching } & \multicolumn{3}{|l|}{ After matching } \\
\hline & \multicolumn{2}{|l|}{ No. $(\%)$} & \multirow[t]{2}{*}{ SD } & \multicolumn{2}{|l|}{ No. $(\%)$} & \multirow[t]{2}{*}{ SD } \\
\hline & $\mathrm{RG}(n=2675)$ & LG $(n=7206)$ & & $\mathrm{RG}(n=2671)$ & LG $(n=2671)$ & \\
\hline $\mathrm{T} 2$ & $425(15.9 \%)$ & $1023(14.2 \%)$ & & $425(15.9 \%)$ & $386(14.5 \%)$ & \\
\hline $\mathrm{T} 3$ & $333(12.4 \%)$ & $1160(16.1 \%)$ & & $331(12.4 \%)$ & $322(12.1 \%)$ & \\
\hline $\mathrm{T} 4 \mathrm{a}$ & $251(9.4 \%)$ & $872(12.1 \%)$ & & $251(9.4 \%)$ & $227(8.5 \%)$ & \\
\hline \multicolumn{7}{|l|}{ Clinical $\mathrm{N}$ factor ${ }^{\mathrm{h}}$} \\
\hline No & $2076(77.6 \%)$ & $5184(71.9 \%)$ & 0.158 & $2073(77.6 \%)$ & $2138(80.0 \%)$ & 0.064 \\
\hline N1 & $322(12.0 \%)$ & $947(13.1 \%)$ & & $322(12.1 \%)$ & $280(10.5 \%)$ & \\
\hline $\mathrm{N} 2$ & $181(6.8 \%)$ & $620(8.6 \%)$ & & $181(6.8 \%)$ & $173(6.5 \%)$ & \\
\hline N3 & $96(3.6 \%)$ & $455(6.3 \%)$ & & $95(3.6 \%)$ & $80(3.0 \%)$ & \\
\hline Esophagogastric junction cancer & $53(2.0 \%)$ & $115(1.6 \%)$ & -0.029 & $53(2.0 \%)$ & $49(1.8 \%)$ & -0.011 \\
\hline Preoperative chemotherapy ${ }^{\mathrm{g}}$ & $77(2.9 \%)$ & $193(2.7 \%)$ & -0.012 & $76(2.8 \%)$ & $69(2.6 \%)$ & -0.016 \\
\hline \multicolumn{7}{|l|}{ Type of resection } \\
\hline Distal gastrectomy & $2286(85.5 \%)$ & $5747(79.8 \%)$ & 0.151 & $2283(85.5 \%)$ & $2283(85.5 \%)$ & 0.000 \\
\hline Total gastrectomy & $389(14.5 \%)$ & $1459(20.2 \%)$ & & $388(14.5 \%)$ & $388(14.5 \%)$ & \\
\hline Concurrent surgical procedures ${ }^{\mathrm{i}}$ & $117(4.4 \%)$ & $849(11.8 \%)$ & 0.274 & $117(4.4 \%)$ & $117(4.4 \%)$ & 0.000 \\
\hline Hospital case volume ( $\geq 20$ cases/year $)^{j}$ & $2624(98.1 \%)$ & $5732(79.5 \%)$ & -0.616 & $2621(98.1 \%)$ & $2621(98.1 \%)$ & 0.000 \\
\hline
\end{tabular}

$B M I$ body mass index, $A S A-P S$ American Society of Anesthesiologists physical status, $A D L$ activities of daily living, $C O P D$ chronic obstructive pulmonary disease, $P T$-INR prothrombin time-international normalized ratio, $R G$ robotic gastrectomy, $L G$ laparoscopic gastrectomy, $S D$ standardized difference

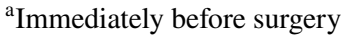

${ }^{\mathrm{b}}$ Within a year of operation

${ }^{\mathrm{c}}$ Within 6 months of operation

${ }^{\mathrm{d}}$ Within 30 days of operation

${ }^{\mathrm{e}}$ Within 48 h of operation

${ }^{\mathrm{f}}$ Within 14 days of operation

${ }^{\mathrm{g}}$ Within 90 days of operation

${ }^{\mathrm{h}}$ The 8th edition of the Union for International Cancer Control-TNM classification

${ }^{\mathrm{i} C h o l e c y s t e c t o m y, ~ s p l e n e c t o m y, ~ a n d ~ e n t e r o s t o m y ~}$

${ }^{\mathrm{j}}$ The number of patients who underwent surgery in hospitals where more than 20 minimally invasive procedures, including RG and LG, were conducted annually

year [5]. Consequently, most of the enrolled patients underwent RG or LG in the high-to-middle volume centers after PSM.

The primary goal of this study was to determine if the advantageous short-term outcome of RG over LG (reduction in morbidity) achieved in our previous multi-institutional prospective study (UMIN000015388) [4] was well reproduced in a real-world setting with good enumeration after the MHLW had recognized RG as a part of LG under the universal health insurance coverage. In this regard, the outcome of this study was almost reversed, although the difference was not statistically significant. However, the morbidity over C-D grade IIIa of 3.9\% in LG is even better than those in the previous studies (UMIN000015388 [4], 6.4\%; Shibasaki et al. [29], 7.6\%; Guerrini's meta-analysis
[30], 6.4\%; Shibasaki's systematic review [31], 1.1-17.5\%; JCOG0703 trial [3] LDG for cStage I GC, Common Terminology Criteria for Adverse Events [CTCAE] v3.0 Grade $\geq 3,5.1 \%$; JCOG1401 trial [32] laparoscopic proximal or total gastrectomy for cStage I GC, CTCAE v4.0 Grade $\geq 3,29.1 \%$ ), suggesting that those who underwent LG operated on by the ESSQS-qualified surgeons in the high-to-middle volume centers were managed very well. In contrast, the morbidity over C-D grade IIIa of $4.9 \%$ in $\mathrm{RG}$ is relatively higher than those previously reported (UMIN000015388 [4], 2.45\%; Shibasaki et al. [29], 3.7\%; Guerrini's meta-analysis [30], 4.1\%). This may be at least partly because the enrolled patients underwent RG within 1 year after RG was insured, and a considerable number of the operating surgeons may not have reached a learning 
Table 2 Surgical outcomes

\begin{tabular}{|c|c|c|c|c|c|}
\hline & \multicolumn{2}{|l|}{ Before matching } & \multicolumn{2}{|l|}{ After matching } & \multirow[t]{3}{*}{$p$ value } \\
\hline & \multicolumn{2}{|c|}{ No. $(\%) /$ median (IQR) } & \multicolumn{2}{|c|}{ No. $(\%) /$ median (IQR) } & \\
\hline & $\mathrm{RG}(N=2675)$ & LG $(N=7206)$ & $\mathrm{RG}(N=2671)$ & $\mathrm{LG}(N=2671)$ & \\
\hline Conversion to open surgery & $9(0.3 \%)$ & $101(1.4 \%)$ & $9(0.3 \%)$ & $13(0.5 \%)$ & 0.523 \\
\hline Intraoperative adverse event $\mathrm{a}^{\mathrm{a}}$ & $0(0.0 \%)$ & $4(0.1 \%)$ & $0(0.0 \%)$ & $1(0.0 \%)$ & 1.000 \\
\hline Operative time, $\min$ & $354(295-427)$ & $279(227-340)$ & $354(295-426)$ & $268(221-326)$ & $<0.001$ \\
\hline Estimate blood loss, $\mathrm{mL}$ & $20(5-50)$ & $20(5-60)$ & $20(5-50)$ & $15(5-50)$ & 0.149 \\
\hline Massive intraoperative bleeding ${ }^{\mathrm{b}}$ & $8(0.3 \%)$ & $33(0.5 \%)$ & $8(0.3 \%)$ & $8(0.3 \%)$ & 1.000 \\
\hline Intraoperative blood transfusion & $45(1.7 \%)$ & $188(2.6 \%)$ & $45(1.7 \%)$ & $36(1.3 \%)$ & 0.356 \\
\hline Intraoperative RCC transfusion, unit & $0(0-0)$ & $0(0-0)$ & $0(0-0)$ & $0(0-0)$ & 0.474 \\
\hline \multicolumn{6}{|l|}{ Residual tumor } \\
\hline R0 & $2652(99.1 \%)$ & $7128(98.9 \%)$ & $2648(99.1 \%)$ & $2654(99.4 \%)$ & 0.607 \\
\hline $\mathrm{R} 1$ & $18(0.7 \%)$ & $69(1.0 \%)$ & $18(0.7 \%)$ & $14(0.5 \%)$ & \\
\hline $\mathrm{R} 2$ & $5(0.2 \%)$ & $9(0.1 \%)$ & $5(0.2 \%)$ & $3(0.1 \%)$ & \\
\hline
\end{tabular}

$R C C$ red cell concentrate, $I Q R$ interquartile range, $R G$ robotic gastrectomy, $L G$ laparoscopic gastrectomy

${ }^{a}$ Intraoperative cardiac arrest or myocardial infarction

${ }^{\mathrm{b}} \geq 1000 \mathrm{~mL}$

plateau of RG, even though they were qualified by the ESSQS. However, the morbidity of $4.9 \%$ in RG is still better than those in LG shown in the aforementioned previous studies [3, 4, 29-32], suggesting that the requirements for insured RG may contribute to safe introduction of $R G$ in general practice. The morbidity of RG is likely to become lower than that of $\mathrm{LG}$ as the skills for RG matures on a nationwide basis, since an increasing number of studiesincluding UMIN000015388, conducted mostly in the leading institutions for RG by expert surgeons in Japan-have successfully revealed favorable outcomes for RG [2, 4, 29, 33-36]. We believe that methodologies to boost the fundamental skills, surgical concepts, and technical principles up to levels comparable to those of expert RG surgeons are needed. To this end, the educational system or adequate clinical experience could play a key role in bringing out the clinical benefits of RG in a real-world setting.

In this study, the 30-day mortality of LG (LG, $0.1 \%$; LDG, $0.0 \%$; LTG, $0.8 \%$ ), was better than reported in the other large database studies (US National Cancer Database [37], 2.7\%; Japanese NCD [11, 18, 19], 0.2-0.9\%); however, it did not differ from RG (RG, 0.2\%; RDG, $0.2 \%$; RTG, $0.5 \%$ ). A similar trend was observed in the estimated blood loss and readmission rate. Although RG had increased reoperation rates, that of $2.2 \%$ in $R G$ is considered acceptable, since those in each type of resection (LDG, 1.2\%; RDG, 2.1\%; LTG, 1.3\%; RTG, 3.4\%) were better than those of LG in the real world (LDG,
$2.7 \%$ [19]; LTG, $4.3 \%$ [21]), which were previously determined using the NCD. These data also suggest that the requirements for insured $\mathrm{RG}$ may contribute to safe introduction of RG in general practice. The duration of postoperative hospitalization was even reduced in $R G$, irrespective of its higher reoperation rate and relatively higher morbidity rate. This may possibly attribute not only to potentially less invasive nature of RG compared to LG [34], but also to better control of the postoperative adverse events after RG. The post hoc evaluation demonstrated that mechanical bowel obstruction was the most common cause of reoperation, especially after RG. This may be at least partly because of port-site hernia after $\mathrm{RG}$, in association with the use of $8-\mathrm{mm}$ or $12-\mathrm{mm}$ trocar rather than 5-mm trocar [38]. Routine closure of the $8-\mathrm{mm}$, as well as $12-\mathrm{mm}$, port sites may help reduce emergent repair due to small bowel incarceration. There was a trend toward increase in the incidence of anastomotic leakage or drainage requiring reoperation in $\mathrm{RG}$, however, the incidence of anastomotic leakage was comparable between RG and LG. In the meantime, there was a trend toward increase in performing red blood cell transfusion after $\mathrm{RG}$, however, the reoperation rate due to postoperative hemorrhage was comparable between $\mathrm{RG}$ and LG. These trends were more remarkable in TG rather than DG. Considering the fact that the number of TG was much smaller than that of DG in this study and that TG is technically more demanding than DG [2, 
Table 3 Postoperative short-term outcomes

\begin{tabular}{|c|c|c|c|c|c|}
\hline & \multirow{2}{*}{\multicolumn{2}{|c|}{$\frac{\text { Before matching }}{\text { No. }(\%) / \text { median (IQR) }}$}} & \multicolumn{3}{|l|}{ After matching } \\
\hline & & & \multicolumn{2}{|c|}{ No. $(\%) /$ median (IQR) } & \multirow[t]{2}{*}{$p$ value } \\
\hline & $\mathrm{RG}(n=2675)$ & LG $(n=7206)$ & $\mathrm{RG}(n=2671)$ & $\mathrm{LG}(n=2671)$ & \\
\hline \multicolumn{6}{|l|}{ Complications } \\
\hline Overall complications $(\geq \text { grade IIIa })^{\mathrm{a}}$ & $135(5.0 \%)$ & $357(5.0 \%)$ & $132(4.9 \%)$ & $105(3.9 \%)$ & $\begin{array}{l}0.084 \text { (OR: } 1.27 \\
{[95 \% \text { CI 0.977- }} \\
1.650])^{\mathrm{f}}\end{array}$ \\
\hline Intra-abdominal infectious complications & $135(5.0 \%)$ & $399(5.5 \%)$ & $133(5.0 \%)$ & $144(5.4 \%)$ & 0.533 \\
\hline Anastomotic leakage & $55(2.1 \%)$ & $191(2.7 \%)$ & $53(2.0 \%)$ & $65(2.4 \%)$ & 0.299 \\
\hline Pancreatic fistula $\mathrm{a}^{\mathrm{b}}(\geq$ grade $\mathrm{B}$ ) & $38(1.4 \%)$ & $121(1.7 \%)$ & $38(1.4 \%)$ & $40(1.5 \%)$ & 0.910 \\
\hline Intra-abdominal abscess & $88(3.3 \%)$ & $238(3.3 \%)$ & $87(3.3 \%)$ & $90(3.4 \%)$ & 0.876 \\
\hline Other local complications & $109(4.1 \%)$ & $335(4.6 \%)$ & $109(4.1 \%)$ & $107(4.0 \%)$ & 0.944 \\
\hline Superficial incisional surgical site infection & $36(1.3 \%)$ & $103(1.4 \%)$ & $36(1.3 \%)$ & $39(1.5 \%)$ & \\
\hline Deep incisional surgical site infection & $5(0.2 \%)$ & $28(0.4 \%)$ & $5(0.2 \%)$ & $7(0.3 \%)$ & \\
\hline Wound dehiscence & $1(0.0 \%)$ & $4(0.1 \%)$ & $1(0.0 \%)$ & $0(0.0 \%)$ & \\
\hline Systemic complications & $101(3.8 \%)$ & $341(4.7 \%)$ & $99(3.7 \%)$ & $91(3.4 \%)$ & 0.602 \\
\hline Pneumonia & $27(1.0 \%)$ & $135(1.9 \%)$ & $27(1.0 \%)$ & $42(1.6 \%)$ & \\
\hline Unexpected endotracheal intubation & $11(0.4 \%)$ & $36(0.5 \%)$ & $11(0.4 \%)$ & $13(0.5 \%)$ & \\
\hline Ventilator dependency & $9(0.3 \%)$ & $28(0.4 \%)$ & $8(0.3 \%)$ & $9(0.3 \%)$ & \\
\hline Pulmonary embolism & $4(0.1 \%)$ & $13(0.2 \%)$ & $4(0.1 \%)$ & $4(0.1 \%)$ & \\
\hline Deep venous thrombosis & $14(0.5 \%)$ & $27(0.4 \%)$ & $14(0.5 \%)$ & $7(0.3 \%)$ & \\
\hline $\begin{array}{l}\text { Postoperative red blood cell transfusion } \\
\text { ( } \geq 140 \mathrm{~mL} \text { within } 72 \mathrm{~h} \text { after surgery) }\end{array}$ & $33(1.2 \%)$ & $100(1.4 \%)$ & $33(1.2 \%)$ & $17(0.6 \%)$ & \\
\hline Sepsis & $10(0.4 \%)$ & $33(0.5 \%)$ & $10(0.4 \%)$ & $9(0.3 \%)$ & \\
\hline Reoperation $^{\mathrm{c}}$ & $61(2.3 \%)$ & $131(1.8 \%)$ & $60(2.2 \%)$ & $32(1.2 \%)$ & 0.004 \\
\hline Mechanical bowel obstruction & $22(0.8 \%)$ & $30(0.4 \%)$ & $22(0.8 \%)$ & $11(0.4 \%)$ & \\
\hline Postoperative hemorrhage & $6(0.2 \%)$ & $18(0.2 \%)$ & $6(0.2 \%)$ & $6(0.2 \%)$ & \\
\hline Anastomotic leakage or drainage & $16(0.6 \%)$ & $41(0.6 \%)$ & $16(0.6 \%)$ & $8(0.3 \%)$ & \\
\hline Readmission $^{\mathrm{c}}$ & $48(1.8 \%)$ & $130(1.8 \%)$ & $48(1.8 \%)$ & $43(1.6 \%)$ & 0.672 \\
\hline 30-day mortality & $6(0.2 \%)$ & $25(0.3 \%)$ & $6(0.2 \%)$ & $4(0.1 \%)$ & 0.754 \\
\hline In-hospital mortality ${ }^{\mathrm{d}}$ & $5(0.2 \%)$ & $34(0.5 \%)$ & $5(0.2 \%)$ & $5(0.2 \%)$ & 1.000 \\
\hline Surgical mortality ${ }^{\mathrm{e}}$ & $6(0.2 \%)$ & $37(0.5 \%)$ & $6(0.2 \%)$ & $5(0.2 \%)$ & 1.000 \\
\hline Intensive care unit stay, days & $0(0-1)$ & $0(0-1)$ & $0(0-1)$ & $0(0-1)$ & 0.195 \\
\hline Postoperative hospitalization, days & $10(8-13)$ & $11(9-15)$ & $10(8-13)$ & $11(9-14)$ & $<0.001$ \\
\hline
\end{tabular}

$I Q R$ interquartile range, $R G$ robotic gastrectomy, $L G$ laparoscopic gastrectomy

${ }^{a}$ The Clavien-Dindo classification

${ }^{\mathrm{b}}$ The International Study Group on Pancreatic Surgery definition and grading of postoperative pancreatic fistula

${ }^{\mathrm{c}}$ Within 30 days after surgery

${ }^{\mathrm{d}}$ Within 90 days after surgery

${ }^{\mathrm{e}}$ Death within 30 days or in-hospital death within 90 days after surgery

${ }^{\mathrm{f}}$ Conditional logistic regression model

$11,21,32]$, learning curve of RG may have affected the increase in severe anastomotic leakage as well as mild postoperative bleeding.

There are several limitations to the present study. First, this study was conducted retrospectively, and we were unable to discuss unmeasured outcomes. Second, long-term outcomes and cost-effectiveness could not be assessed, since prognosis, recurrence pattern, late complications, and cost were not documented in the NCD. Third, detailed PG data are also lacking in this database.

In conclusion, considering the fact that $\mathrm{LG}$ and $\mathrm{RG}$ are mature and growing treatment measures, respectively, RG was safely performed while meeting the requirements for insurance coverage. 
Table 4 Postoperative short-term outcomes on distal gastrectomy and total gastrectomy (after matching)

\begin{tabular}{|c|c|c|c|c|}
\hline & \multicolumn{2}{|c|}{ DG (after matching) } & \multicolumn{2}{|c|}{ TG (after matching) } \\
\hline & \multicolumn{2}{|c|}{ No. $(\%) /$ median (IQR) } & \multicolumn{2}{|c|}{ No. (\%)/median (IQR) } \\
\hline & $\operatorname{RDG}(n=2283)$ & LDG $(n=2283)$ & RTG $(n=388)$ & LTG $(n=388)$ \\
\hline \multicolumn{5}{|l|}{ Complications } \\
\hline Overall complications $(\geq \text { grade IIIa })^{\mathrm{a}}$ & $104(4.6 \%)$ & $81(3.5 \%)$ & $28(7.2 \%)$ & $24(6.2 \%)$ \\
\hline Intra-abdominal infectious complications & $99(4.3 \%)$ & $111(4.9 \%)$ & $34(8.8 \%)$ & $33(8.5 \%)$ \\
\hline Anastomotic leakage & $35(1.5 \%)$ & $48(2.1 \%)$ & $18(4.6 \%)$ & $17(4.4 \%)$ \\
\hline Pancreatic fistula ${ }^{\mathrm{b}}$ ( $\geq$ grade B) & $33(1.4 \%)$ & $34(1.5 \%)$ & $5(1.3 \%)$ & $6(1.5 \%)$ \\
\hline Intra-abdominal abscess & $59(2.6 \%)$ & $69(3.0 \%)$ & $28(7.2 \%)$ & $21(5.4 \%)$ \\
\hline Other local complications & $94(4.1 \%)$ & $86(3.8 \%)$ & $15(3.9 \%)$ & $21(5.4 \%)$ \\
\hline Superficial incisional surgical site infection & $32(1.4 \%)$ & $34(1.5 \%)$ & $4(1.0 \%)$ & $5(1.3 \%)$ \\
\hline Deep incisional surgical site infection & $4(0.2 \%)$ & $5(0.2 \%)$ & $1(0.3 \%)$ & $2(0.5 \%)$ \\
\hline Wound dehiscence & $0(0.0 \%)$ & $0(0.0 \%)$ & $1(0.3 \%)$ & $0(0.0 \%)$ \\
\hline Systemic complications & $66(2.9 \%)$ & $65(2.8 \%)$ & $33(8.5 \%)$ & $26(6.7 \%)$ \\
\hline Pneumonia & $20(0.9 \%)$ & $32(1.4 \%)$ & $7(1.8 \%)$ & $10(2.6 \%)$ \\
\hline Unexpected endotracheal intubation & $7(0.3 \%)$ & $8(0.4 \%)$ & $4(1.0 \%)$ & $5(1.3 \%)$ \\
\hline Ventilator dependency & $5(0.2 \%)$ & $6(0.3 \%)$ & $3(0.8 \%)$ & $3(0.8 \%)$ \\
\hline Pulmonary embolism & $4(0.2 \%)$ & $4(0.2 \%)$ & $0(0.0 \%)$ & $0(0.0 \%)$ \\
\hline Deep venous thrombosis & $13(0.6 \%)$ & $3(0.1 \%)$ & $1(0.3 \%)$ & $4(1.0 \%)$ \\
\hline $\begin{array}{l}\text { Postoperative red blood cell transfusion } \\
\text { ( } \geq 140 \mathrm{~mL} \text { within } 72 \mathrm{~h} \text { after surgery) }\end{array}$ & $19(0.8 \%)$ & $13(0.6 \%)$ & $14(3.6 \%)$ & $4(1.0 \%)$ \\
\hline Sepsis & $3(0.1 \%)$ & $7(0.3 \%)$ & $7(1.8 \%)$ & $2(0.5 \%)$ \\
\hline Reoperation $^{\mathrm{c}}$ & $47(2.1 \%)$ & $27(1.2 \%)$ & $13(3.4 \%)$ & $5(1.3 \%)$ \\
\hline Mechanical bowel obstruction & $19(0.8 \%)$ & $6(0.3 \%)$ & $3(0.8 \%)$ & $5(1.3 \%)$ \\
\hline Postoperative hemorrhage & $3(0.1 \%)$ & $5(0.2 \%)$ & $3(0.8 \%)$ & $1(0.3 \%)$ \\
\hline Anastomotic leakage or drainage & $12(0.5 \%)$ & $8(0.4 \%)$ & $4(1.0 \%)$ & $0(0.0 \%)$ \\
\hline Readmission $^{\mathrm{c}}$ & $42(1.8 \%)$ & $34(1.5 \%)$ & $6(1.5 \%)$ & $9(2.3 \%)$ \\
\hline 30-day mortality & $4(0.2 \%)$ & $1(0.0 \%)$ & $2(0.5 \%)$ & $3(0.8 \%)$ \\
\hline In-hospital mortality ${ }^{\mathrm{d}}$ & $3(0.1 \%)$ & $2(0.1 \%)$ & $2(0.5 \%)$ & $3(0.8 \%)$ \\
\hline Surgical mortality ${ }^{\mathrm{e}}$ & $4(0.2 \%)$ & $2(0.1 \%)$ & $2(0.5 \%)$ & $3(0.8 \%)$ \\
\hline Intensive care unit stay, days & $0(0-1)$ & $0(0-1)$ & $0(0-1)$ & $0(0-1)$ \\
\hline Postoperative hospitalization, days & $10(8-12)$ & $10(9-13)$ & $11(9-14)$ & $12(9-16)$ \\
\hline
\end{tabular}

$I Q R$ interquartile range, $R G$ robotic gastrectomy, $L G$ laparoscopic gastrectomy

${ }^{a}$ The Clavien-Dindo classification

${ }^{\mathrm{b}}$ The International Study Group on Pancreatic Surgery definition and grading of postoperative pancreatic fistula

${ }^{c}$ Within 30 days after surgery

${ }^{\mathrm{d}}$ Within 90 days after surgery

${ }^{\mathrm{e}}$ Death within 30 days or in-hospital death within 90 days after surgery

Acknowledgements The authors thank all data managers and hospitals for participating in the NCD project and for their great effort in entering the data. We also thank the working members of the NCD Committee of the JSES and the Database Committee of the JSGS. This study was supported by the JSES. We thank Mr. Miyoshi Sakai and Ms. Chie Yamamoto of EP-CRSU Co., Ltd. (Tokyo, Japan) for their dedicated administrative support. The authors are indebted to Editage (http:// www.editage.com) for English language editing.

Author contributions All authors have fully met the ICMJE authorship criteria as follows: 1 . study design: KS, HY, TN, KO, YY, MH, SS, TT, YK, MI, YK, HM, MT, HN, IU; data collection: HY; statistical analysis and interpretation of results: HY, KS, TN, KO, YY, MH, SS, TT, HM,
MT, HN, IU. 2. Drafting of the manuscript, KS; critical revision of the manuscript for important intellectual content, KS, HY, TN, KO, YY, MH, SS, TT, YK, MI, YK, HM, MT, HN, IU. All authors have read and approved the final manuscript. All authors are accountable for all aspects of the work in ensuring that questions related to the accuracy or integrity of any part of the work are appropriately investigated and resolved.

\section{Declarations}

Conflict of interest H.Y., and H.M. are affiliated with the Department of Healthcare Quality Assessment at the University of Tokyo, which 
is a social collaboration department supported by grants from NCD, Johnson \& Johnson K.K., and Nipro Co. The remaining authors have no commercial association with or financial involvement that might pose a conflict of interest in connection with the submitted article. K.S. has been funded by Sysmex, Co. in relation to the Collaborative Laboratory for Research and Development in Advanced Surgical Intelligence, Fujita Health University. T.T. and I.U. have also been funded by Medicaroid, Inc. in relation to the Collaborative Laboratory for Research and Development in Advanced Surgical Technology, Fujita Health University. K.S. received advisory fees from Medicaroid, Inc., outside of the submitted work. I.U. received lecture fees from Intuitive Surgical, Inc., outside of the submitted work. This study was funded by Intuitive Surgical Sarl for administrative support provided by EPCRSU Co., Ltd. The funder was not involved in the study design, collection, analysis, interpretation of data, the writing of this article, or the decision to submit it for publication.

Ethical approval All procedures were conducted in accordance with the ethical standards of the respective committees on human experimentation (institutional and national) and with the Helsinki Declaration of 1964 and later versions. The study was approved by the institutional review boards of all participating institutes. The requirement for informed consent was waived because the customized database contained de-identified and anonymized data.

\section{References}

1. Sung H, Ferlay J, Siegel RL, Laversanne M, Soerjomataram I, Jemal A, et al. Global cancer statistics 2020: GLOBOCAN estimates of incidence and mortality worldwide for 36 cancers in 185 countries. CA Cancer J Clin. 2021;71:209-49.

2. Suda K, Man IM, Ishida Y, Kawamura Y, Satoh S, Uyama I. Potential advantages of robotic radical gastrectomy for gastric adenocarcinoma in comparison with conventional laparoscopic approach: a single institutional retrospective comparative cohort study. Surg Endosc. 2015;29:673-85.

3. Katai H, Sasako M, Fukuda H, Nakamura K, Hiki N, Saka M, et al. Safety and feasibility of laparoscopy-assisted distal gastrectomy with suprapancreatic nodal dissection for clinical stage I gastric cancer: a multicenter phase II trial (JCOG 0703). Gastric Cancer. 2010;13:238-44.

4. Uyama I, Suda K, Nakauchi M, Kinoshita T, Noshiro H, Takiguchi $\mathrm{S}$, et al. Clinical advantages of robotic gastrectomy for clinical stage I/II gastric cancer: a multi-institutional prospective singlearm study. Gastric Cancer. 2019;22:377-85.

5. Kikuchi K, Suda K, Shibasaki S, Tanaka T, Uyama I. Challenges in improving the minimal invasiveness of the surgical treatment for gastric cancer using robotic technology. Ann Gastroenterol Surg. 2021;5:604-13. https://doi.org/10.1002/ags3.12463.

6. Mori T, Kimura T, Kitajima M. Skill accreditation system for laparoscopic gastroenterologic surgeons in Japan. Minim Invasive Ther Allied Technol. 2010;19:18-23.

7. Shibasaki S, Suda K, Kadoya S, Ishida Y, Nakauchi M, Nakamura $\mathrm{K}$, et al. The safe performance of robotic gastrectomy by secondgeneration surgeons meeting the operating surgeon's criteria in the Japan Society for Endoscopic Surgery guidelines. Asian J Endosc Surg. 2021. https://doi.org/10.1111/ases.12967.

8. Ikegami N, Yoo BK, Hashimoto H, Matsumoto M, Ogata H, Babazono A, et al. Japanese universal health coverage: evolution, achievements, and challenges. Lancet. 2011;378:1106-15.

9. Nakauchi M, Suda K, Susumu S, Kadoya S, Inaba K, Ishida Y, et al. Comparison of the long-term outcomes of robotic radical gastrectomy for gastric cancer and conventional laparoscopic approach: a single institutional retrospective cohort study. Surg Endosc. 2016;30:5444-52.

10. Kakeji Y, Takahashi A, Hasegawa H, Ueno H, Eguchi S, Endo I, et al. Surgical outcomes in gastroenterological surgery in Japan: report of the National Clinical Database 2011-2018. Ann Gastroenterol Surg. 2020;4:250-74.

11. Kodera Y, Yoshida K, Kumamaru H, Kakeji Y, Hiki N, Etoh T, et al. Introducing laparoscopic total gastrectomy for gastric cancer in general practice: a retrospective cohort study based on a nationwide registry database in Japan. Gastric Cancer. 2019;22:202-13.

12. Gotoh M, Miyata H, Hashimoto H, Wakabayashi G, Konno H, Miyakawa S, et al. National Clinical Database feedback implementation for quality improvement of cancer treatment in Japan: from good to great through transparency. Surg Today. 2016;46:38-47.

13. National Clinical Database. http://www.ncd.or.jp/. Accessed 29 Aug 2021.

14. Brierley JD, Gospodarowicz MK, Wittekind C. TNM classification of malignant tumours. 8th ed. Hoboken: Wiley-Blackwell; 2017.

15. Dindo D, Demartines N, Clavien PA. Classification of surgical complications: a new proposal with evaluation in a cohort of 6336 patients and results of a survey. Ann Surg. 2004;240:205-13.

16. Lee JH, Park DJ, Kim HH, Lee HJ, Yang HK. Comparison of complications after laparoscopy-assisted distal gastrectomy and open distal gastrectomy for gastric cancer using the Clavien-Dindo classification. Surg Endosc. 2012;26:1287-95.

17. Clavien PA, Barkun J, de Oliveira ML, Vauthey JN, Dindo D, Schulick RD, et al. The Clavien-Dindo classification of surgical complications: five-year experience. Ann Surg. 2009;250:187-96.

18. Yoshida K, Honda M, Kumamaru H, Kodera Y, Kakeji Y, Hiki $\mathrm{N}$, et al. Surgical outcomes of laparoscopic distal gastrectomy compared to open distal gastrectomy: a retrospective cohort study based on a nationwide registry database in Japan. Ann Gastroenterol Surg. 2018;2:55-64.

19. Hiki N, Honda M, Etoh T, Yoshida K, Kodera Y, Kakeji Y, et al. Higher incidence of pancreatic fistula in laparoscopic gastrectomy. Real-world evidence from a nationwide prospective cohort study. Gastric Cancer. 2018;21:162-70.

20. Iwatsuki M, Yamamoto H, Miyata H, Kakeji Y, Yoshida K, Konno $\mathrm{H}$, et al. Association of surgeon and hospital volume with postoperative mortality after total gastrectomy for gastric cancer: data from 71,307 Japanese patients collected from a nationwide webbased data entry system. Gastric Cancer. 2021;24:526-34.

21. Etoh T, Honda M, Kumamaru H, Miyata H, Yoshida K, Kodera Y, et al. Morbidity and mortality from a propensity score-matched, prospective cohort study of laparoscopic versus open total gastrectomy for gastric cancer: data from a nationwide web-based database. Surg Endosc. 2018;32:2766-73.

22. Nishigori T, Miyata H, Okabe H, Toh Y, Matsubara H, Konno H, et al. Impact of hospital volume on risk-adjusted mortality following oesophagectomy in Japan. Br J Surg. 2016;103:1880-6.

23. Leuven E, Sianesi B. "PSMATCH2: Stata module to perform full Mahalanobis and propensity score matching, common support graphing, and covariate imbalance testing" Statistical Software Components S432001. Boston College Department of Economics. 2003. http://ideas.repec.org/c/boc/bocode/s432001.html. Accessed 5 Sept 2021.

24. Bayoumi A. "STDDIFF: Stata module to compute Standardized differences for continuous and categorical variables," Statistical Software Components S458275. Boston College Department of Economics, revised 09 Mar 2021. 2016. https://ideas.repec.org/c/ boc/bocode/s458275.html. Accessed 5 Sept 2021. 
25. Shibasaki S, Suda K, Nakauchi M, Nakamura K, Tanaka T, Kikuchi K, et al. Impact of the Endoscopic Surgical Skill Qualification System on the safety of laparoscopic gastrectomy for gastric cancer. Surg Endosc. 2020. https://doi.org/10.1007/ s00464-020-08102-5.

26. Zhou J, Shi Y, Qian F, Tang B, Hao Y, Zhao Y, et al. Cumulative summation analysis of learning curve for robot-assisted gastrectomy in gastric cancer. J Surg Oncol. 2015;111:760-7.

27. Kim HI, Park MS, Song KJ, Woo Y, Hyung WJ. Rapid and safe learning of robotic gastrectomy for gastric cancer: multidimensional analysis in a comparison with laparoscopic gastrectomy. Eur J Surg Oncol. 2014;40:1346-54.

28. Park SS, Kim MC, Park MS, Hyung WJ. Rapid adaptation of robotic gastrectomy for gastric cancer by experienced laparoscopic surgeons. Surg Endosc. 2012;26:60-7.

29. Shibasaki S, Suda K, Nakauchi M, Nakamura K, Kikuchi K, Inaba $\mathrm{K}$, et al. Non-robotic minimally invasive gastrectomy as an independent risk factor for postoperative intra-abdominal infectious complications: a single-center, retrospective and propensity scorematched analysis. World J Gastroenterol. 2020;26:1172-84.

30. Guerrini GP, Esposito G, Magistri P, Serra V, Guidetti C, Olivieri $\mathrm{T}$, et al. Robotic versus laparoscopic gastrectomy for gastric cancer: the largest meta-analysis. Int J Surg. 2020;82:210-28.

31. Shibasaki S, Suda K, Obama K, Yoshida M, Uyama I. Should robotic gastrectomy become a standard surgical treatment option for gastric cancer? Surg Today. 2020;50:955-65.

32. Katai H, Mizusawa J, Katayama H, Kunisaki C, Sakuramoto $\mathrm{S}$, Inaki N, et al. Single-arm confirmatory trial of laparoscopyassisted total or proximal gastrectomy with nodal dissection for clinical stage I gastric cancer: Japan Clinical Oncology Group study JCOG1401. Gastric Cancer. 2019;22:999-1008.

33. Ojima T, Nakamura M, Hayata K, Kitadani J, Katsuda M, Takeuchi A, et al. Short-term outcomes of robotic gastrectomy vs laparoscopic gastrectomy for patients with gastric cancer: a randomized clinical trial. JAMA Surg. 2021. https://doi.org/10. 1001/jamasurg.2021.3182.

34. Lu J, Zheng CH, Xu BB, Xie JW, Wang JB, Lin JX, et al. Assessment of robotic versus laparoscopic distal gastrectomy for gastric cancer: a randomized controlled trial. Ann Surg. 2021;273:858-67.

35. Kinoshita T, Sato R, Akimoto E, Tanaka Y, Okayama T, Habu $\mathrm{T}$. Reduction in postoperative complications by robotic surgery: a case-control study of robotic versus conventional laparoscopic surgery for gastric cancer. Surg Endosc. 2021. https://doi.org/10. 1007/s00464-021-08483-1.

36. Hikage M, Fujiya K, Kamiya S, Tanizawa Y, Bando E, Notsu A, et al. Robotic gastrectomy compared with laparoscopic gastrectomy for clinical stage I/II gastric cancer patients: a propensity score-matched analysis. World J Surg. 2021;45:1483-94.

37. Ryan S, Tameron A, Murphy A, Hussain L, Dunki-Jacobs E, Lee DY. Robotic versus laparoscopic gastrectomy for gastric adenocarcinoma: propensity-matched analysis. Surg Innov. 2020;27:26-31.

38. Diez-Barroso R Jr, Palacio CH, Martinez JA, Makris K, Massarweh NN, Chai CY, et al. Robotic port-site hernias after general surgical procedures. J Surg Res. 2018;230:7-12.

Publisher's Note Springer Nature remains neutral with regard to jurisdictional claims in published maps and institutional affiliations. 